Boletim Científico do Instituto Agronômico do Estado de São Paulo

Vol. 25

Campinas, agôsto de 1966

N. 18

\title{
PARTÍCULAS ESFEROIDAIS ASSOCIADAS AO VÍRUS DO MOSAICO DAS NERVURAS DA MANDIOCA $\left({ }^{1}\right)$
}

E. W. Kitajima e A. S. Costa, engenheiros-agrônomos, Seção de Virologia, Instituto Agronômico de Campinas

\section{SINOPSE}

Partículas esferoidais de $50-60 \mathrm{~m}_{\mu}$ de diâmetro foram encontradas em preparações rápidas e em secções ultra-finas de fôlhas de mandioca infetadas pelo virus do mosaico das nervuras (VMNM), examinadas ao microscópio electrônico. Tais partículas não foram observadas em preparações de plantas sadias ou de fôlhas sem sintomas de plantas infetadas, e são consideradas como representando o VMNM.

Em secções ultra-finas de tecido foliar, as partículas do VMNM encontravam-se dispersas em certas áreas do citoplasma, ricas em ribosomas mas pobres em outras organelas citoplasmáticas, e onde esporàdicamente apareciam pequenos feixes de fibrilas densas (7-10 $\left.\mathrm{m}_{\mu} \times 100-300 \mathrm{~m}_{\mu}\right)$. Massas densas, de textura finamente granulada $(0,3-3 \mu$ de diâmetro), foram encontradas em alguns casos associadas às partículas. Provàvelmente, tanto as massas densas como as fibrilas estão implicadas na sintese do VMNM.

\section{1 - INTRODUÇÃO}

Plantas de mandioca (Manihot utilissima Pohl.) são encontradas ocasionalmente infetadas pelo vírus do mosaico das nervuras (VMNM) no Estado de São Paulo (fig. 1). Estudos efetuados revelaram que êste vírus sòmente é perpetuado através do uso de manivas infetadas, sendo de fácil contrôle. Sua importância econômica parece ser reduzida (4).

Partículas esferoidais foram encontradas associadas a essa moléstia, tanto em preparações rápidas como em secções ultra-finas de tecidos infetados, em exames ao microscópio electrônico. A morfologia destas partículas, fora ou no interior dos tecidos invadidos, bem como aspectos das células foliares afetadas, é descrita no presente artigo.

(1) Trabalho parcialmente axiliado pelo CNPq (TC 4026) e pela FAPESP (C. Agron. 64/454). Recebido para publicação em 2 de maio de 1966. 


\section{2 - MATERIAL E MÉTODOS}

a) Plantas utilizadas - Foram utilizadas plantas de mandioca, das variedades 850 e $853\left({ }^{2}\right)$, encontradas no campo, naturalmente infetadas pelo VMNM, e Guaxupé, para as quais a moléstia foi transmitida por enxertia. Plantas desta variedade, não inoculadas, foram utilizadas como contrôles sadios.

b) “Dipping"-contrastação negativa - Preparações rápidas para microscopia electrônica foram feitas a partir das plantas acima mencionadas, combinando-se os métodos de "dipping e contrastação negativa (8).

c) Secções ultra-finas - Pedaços de fôlhas (1 $\mathrm{mm} \times 3 \mathrm{~mm})$ de plantas sadias ou infetadas pelo VMNM (de áreas com manchas cloróticas, com mosaico nas nervuras ou sem sintomas), foram fixados em tetróxido de ósmio a $2 \%$ em tampão fosfato, durante $12-18$ horas, a $0-4^{\circ} \mathrm{C}(\mathbf{1 3})$, desidratadas em acetona e incluidas em Epon 812 (10).

Os blocos foram seccionados em um ultramicrótomo Porter-Blum, mod. MT-1, utilizando-se navalhas de vidro. Secções mais espêssas $(2-5 \mu)$ foram montadas para microscopia óptica, e coradas com uma mistura de Azur II e Azul de metileno (16) para servirem de contrôle. Secções ultra-finas (500-1000A) foram coradas com citrato de chumbo (14) e examinadas em um microscópio electrônico ELMISKOP I, da Siemens $\left(^{3}\right)$.

\section{3 - RESULTADOS}

Partículas de contôrno circular, de 50-60 $\mathrm{m} \mu$ de diâmetro, foram encontradas em concentração relativamente baixa, em preparações rápidas para microscopia electrônica, feitas a partir de fôlhas de plantas infetadas pelo VMNM (figura 2), mas não nas de plantas sadias. Algumas das partículas exibiam indícios de serem constituídas de subunidades menores. Porém, detalhes como número e disposição destas, ficaram obscurecidos pelas impurezas normalmente presentes em tais preparações, já que se tratava de material não purificado.

Exame de secções ultra-finas de tecido foliar de plantas infetadas pelo VMNM demonstraram a presença de partículas de 45-50 $\mathrm{m}_{\mu}$ de diâmetro no citoplasma de numerosas células (figuras 3-6), ausentes nas células de plantas sadias. A ocorrência destas partículas, por outro lado, estava associada à manifestação de sintomas nas fôlhas de plantas infetadas, pois em amostras de 
áreas sem sintomas não se pôde constatar a sua presença. Os exames mostraram que as partículas podiam ser encontradas em células de todos os tipos de tecidos da fôlha (epiderme, parênquima paliçádico, lacunoso e do sistema vascular), exceto nos vasos lenhosos e crivados.

Em secções, as partículas apresentavam um perfil circular ou hexagonal, com uma zona central menos densa, de 100-200A de diâmetro, circundado por uma zona bem densa, de 100-150A de espessura, e mais externamente por uma zona de densidade intermediária, de cêrca de 100A de espessura (figuras 3 e 4). Partículas uniformemente densas também foram observadas, porém com menor freqüência.

As partículas acima descritas foram encontradas em grande número em extensas áreas do citoplasma, que se diferenciavam do resto pela riqueza em ribosomas e pela pobreza ou mesmo ausência de outras organelas citoplasmáticas (dictiosoma, retículo endoplasmático, mitocondria). Estas, em geral, apareciam margeando tais zonas como se tivessem sido deslocadas (figuras 3-6). Por outro lado, não se observou arranjos organizados, bi ou tridimensionais, das partículas, aparecendo estas uniformemente distribuídas no citoplasma ou formando pequenos agregados.

Ocasionalmente, algumas massas densas, de textura finamente granulada, de contôrno aproximadamente circular e de dimensões variadas $(0,2$ a $3 \mu$ de diâmetro), apareciam nas zonas do citoplasma que continham as partículas. Estas apareciam associadas às referidas massas, em geral em sua superfície, causando a impressão de que delas "brotavam" (figura 5). Também, feixes de 3 a 20 fibrilas densas, de 6-10 $\mathrm{m} \mu$ de diâmetro e 100-300 $\mathrm{m} \mu$ de comprimento, puderam ser observados esporàdicamente em meio aos ribosomas e partículas esferoidais (figuras 3 e 4).

Não se observaram em geral alterações profundas nas células, contendo ou não partículas, de fôlhas com sintomas fortes da moléstia, em relação àquelas de áreas sem sintomas ou de plantas sadias, exceto a presença de partículas esferoidais em meio ao citoplasma diferenciado. Mesmo assim, foram observados alguns possíveis efeitos da infeeção, como um certo acúmulo de grãos de amido nos plastídios, acompanhados de uma redução no número de lamelas; ocasional intumescência da parede celular e eventual aparecimento de células em vias de necrose, geralmente deformadas, e com seu conteúdo bastante adensado. Células necrosadas ocorriam muito raramente.

Em algumas células, as áreas do citoplasma que continham as partículas ficavam mais rarefeitas, quando então se tornavam mais fàcilmente visíveis (figura 6) .

Em secções montadas para microscopia óptica, não se constataram diferenças que permitissem distinguir marcadamente as células infetadas pelo VMNM, das sadias. 


\section{4 - DISCUSSÃO}

As partículas esferoidais encontradas nas preparações de "dipping"-contrastação negativa de plantas infetadas pelo VMNM e nas células de tecidos foliares das mesmas plantas, devem ser idênticas. A semelhança morfológica e a estreita associação entre a ocorrência destas partículas nas preparações rápidas e em secções de tecidos infetados podem ser adotadas como argumentos favoráveis a identidade delas.

A ligeira discrepância no diâmetro das partículas observadas in vitro e in situ (50-60 $\mathrm{m} \mu$ e $45-50 \mathrm{~m}_{\mu}$, respectivamente) pode ser atribuída a uma deformação durante a secagem das partículas, nas preparações contrastadas negativamente, ou à sua ligeira contração, durante o processo de fixação. Situação análoga já foi observada para diversos vírus, quando examinados em suspensão e em secções $(6,10,15)$.

Uma prova conclusiva de que estas partículas representam 0 VMNM sòmente poderá ser obtida através de uma cuidadosa análise dos resultados de ensaios associando purificação e infetividade. Não obstante, as seguintes evidências obtidas pela microscopia electrônica são bastante sugestivas de que estas partículas sejam as do VMNM, como doravante serão chamadas:

a) A ocorrência destas partículas sòmente em plantas infetadas com o VMNM, e sua ausência em tecidos de plantas sadias. Em tecidos de mandioca infetados por um outro vírus, o do mosaico comum, de forma alongada, não se constatou partículas similares (9), o que reduz a possibilidade de estas representarem produto de uma reação inespecífica da planta à infecção.

b) A associação bastante estreita entre a ocorrência das partículas, em secções, e áreas das fôlhas ostentando sintomas típicos da moléstia.

c) A analogia na morfologia destas partículas com a de alguns outros vírus já descritos na literatura, como o do "wound tumor" do trêvo (Melilotus sp.) (3, 17); do nanismo do arroz (Oryza sativa L.) (6) ; REO (respiratory and enteric orphan), um vírus animal $(5,15,18)$; e o da faixa amarela das nervuras da couve (Brassica oleracea L. var. capitata) (10).

Determinação acurada da ultraestrutura das partículas do VMNM não pôde ser feita, devido às impurezas presentes nas preparações rápidas utilizadas, que obscureciam detalhes da arquitetura destas partículas (8). Em algumas micrografias favoráveis, porém, o número de subunidades visíveis sugere que o capsídeo das partículas do VMNM seja constituído de 92 capsômeros dispostos na superfície de um icosaedro regular. Se confirmado, o VMNM poderá representar mais um integrante do grupo morfológico do vírus $\operatorname{REO}(1,7,12)$. 


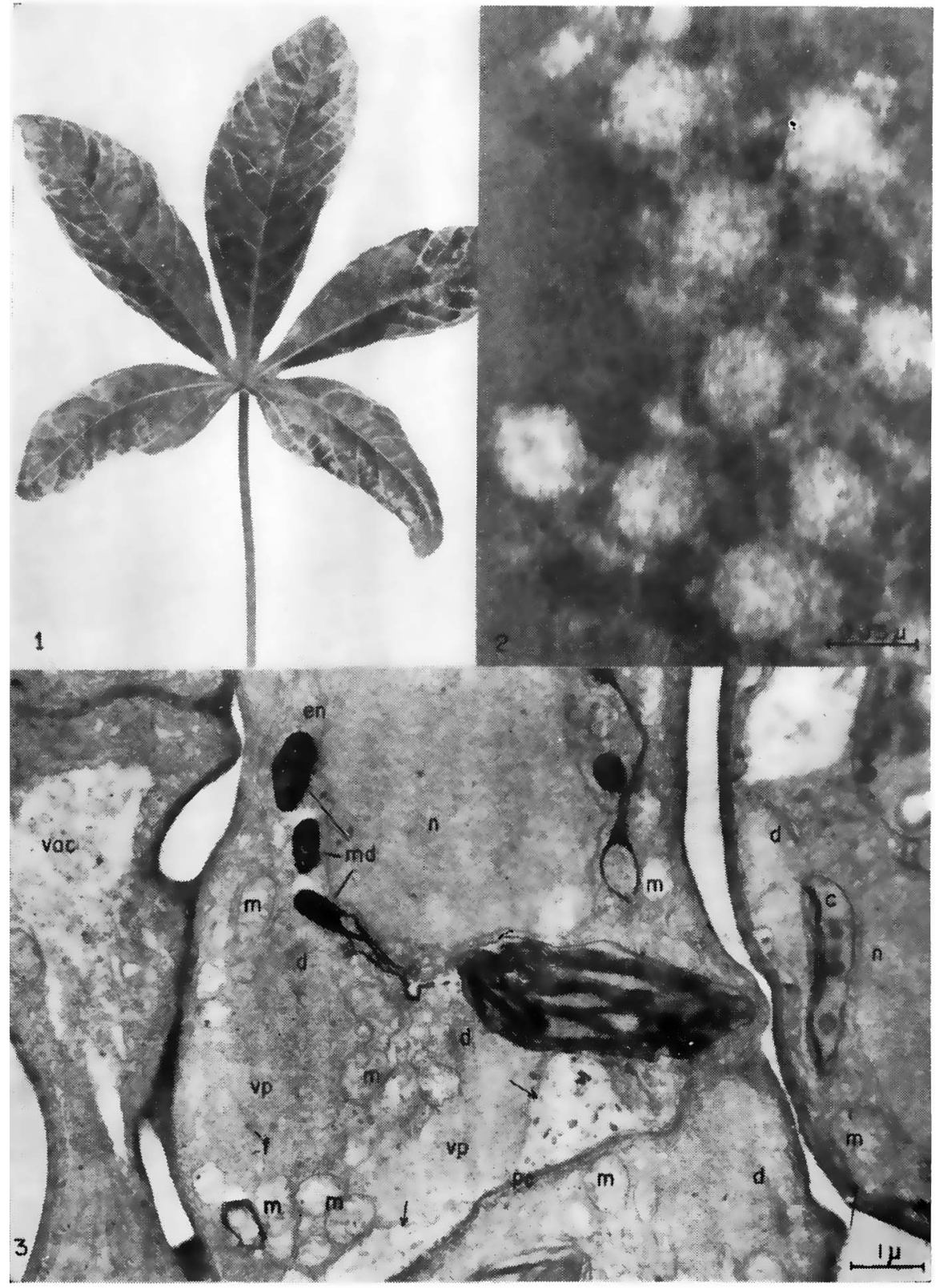

1 - Fôlha de mandioca, ostentando sintomas típicos da infeç̧ão pelo vírus do mosaico das nervuras. 2 - Particulas esferoidais, encontradas em preparações “dipping"-contrastação negativa, de fôlhas de mandioca infetadas com o VMNM. 3 - Micrografia electrônica de uma célula do parênquima lacunoso, invadida pelo VMNM. Notem-se duas grandes áreas do citoplasma, onde as partículas dêste virus $(v p)$ e fibrilas $(f)$ ocorrem, estando as organelas citoplasmáticas deslocadas para a periferia. Parte da parede celular $(p c)$ acha-se intumescida (setas). $d-$ dictiosoma; $c-$ cloroplasto; $n-$ núcleo; en - envólucro nuclear; $m d$ - massa densa contida no vacúolo; $m$ - mitocondria; vac - vacúolo. 


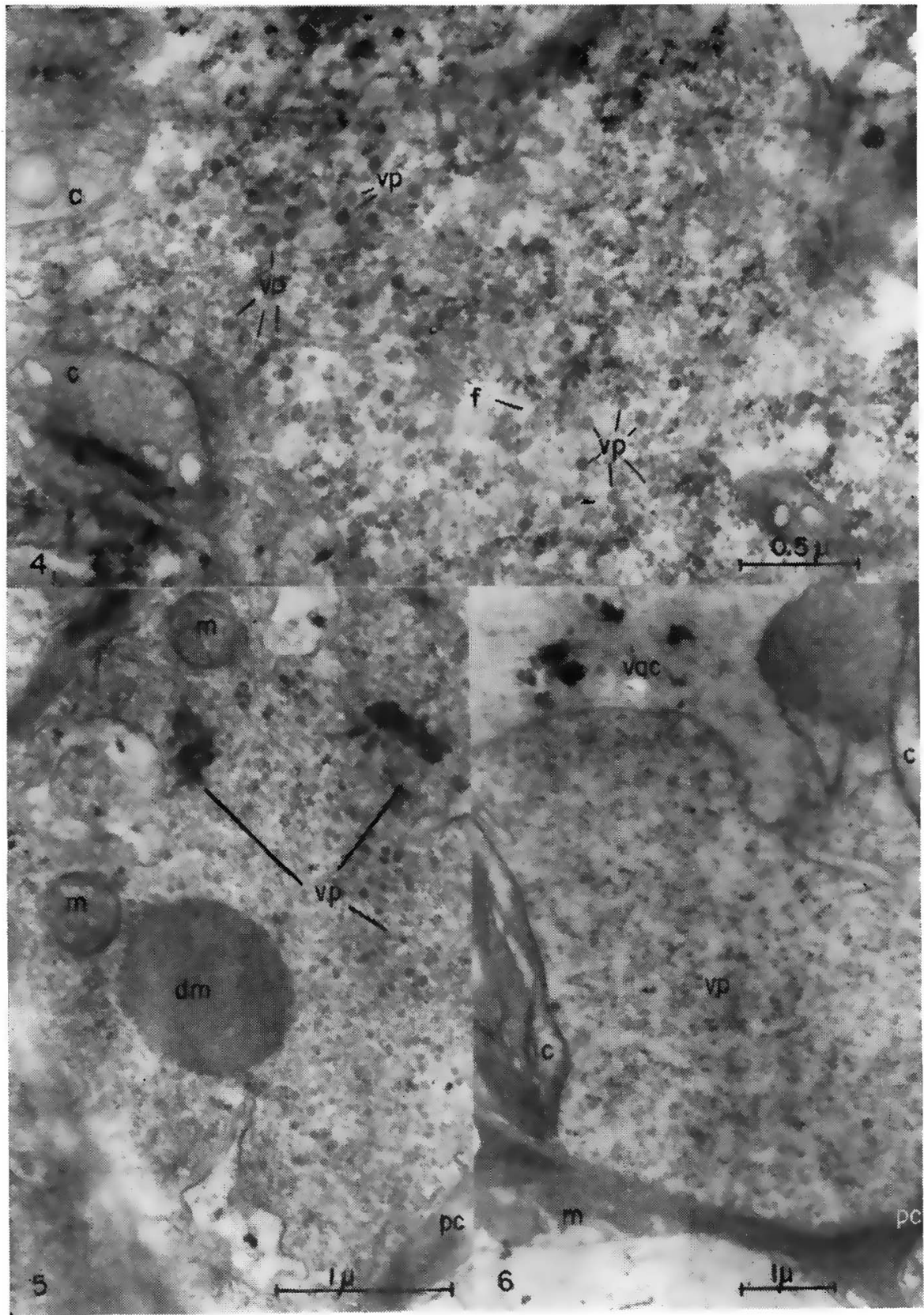

4 - Detalhe de uma zona do citoplasma, onde ocorrem as particulas do viruos do mosaico das nervuras da mandioca $(v p)$, mostrando a existência de fibrilas densas $(f)$. Note-se que muitas partículas do virus têm a porção central menos densa. $c$ - cloroplasto. 5 - Uma parte do citoplasma de uma célula do padensa. $c-$ cloroplasto. 5 to uma inclusão densa e finamente granulada $(\mathrm{dm})$, associada às partículas do VMNM $(v p)$. $m$ - mitocondria; $p c$ _ parede celular. 6 - Porcẫo basal de uma célula do parênquima paliçádico. As partículas do VMNM - $(v p)$ se acham em um substrato mais ralo. $c-$ cloroplasto; vac vacúolo; $m$ - mitocondria. 
As partículas, que em secçoes apresentavam uma zona central menos densa, foram constatadas também com o vírus da faixa amarela das nervuras da couve (10), quando foram aventadas as seguintes hipóteses para explicar êste aspecto: a) que estas partículas representassem formas incompletas desprovidas de ácido nucléico equivalente às formas "ôcas" de certos vírus $(\mathbf{1 8}, 19)$; b) que elas seriam produtos intermediários da síntese do vírus; c) que decorressem de artefatos de técnica. Bernhard (2) julga a última hipótese mais viável, em vista da utilização de acetona como agente desidratante, que poderia ter provocado a extração de material nucléico das partículas.

O fato das partículas do VMNM terem sido encontradas exclusivamente no citoplasma concorda com as observações feitas com outros vírus morfològicamente similares in situ. Sua ocorrência, porém, como partículas discretas, espalhadas em certas áreas do citoplasma, ao contrário dos outros, que tendem a formar agregados cristalinos ou não e associarem-se a inclusões densas $(5,6,10,15,17)$, parece constituir um padrão diferente. Esta característica não é exclusiva do VMNM, pois partículas do vírus do nanismo do arroz foram também ocasionalmente encontradas dispersas no citoplasma, embora quase sempre formem inclusões cristalinas (6), e, por outro lado, partículas do VMNM foram encontradas em alguns casos formando agregados irregulares ou associadas a inclusões densas.

A presença de feixes orientados de filamentos de 50-80A de diâmetro parece ser um fato comum em células de mamíferos mantidas em cultura. Por outro lado, além dêstes, em células L infetadas pelo vírus REO, foram encontrados filamentos similares, intimamente relacionados às partículas do vírus em desenvolvimento (5). Exames de diferentes tecidos de mais de 30 espécies diferentes de plantas, pertencentes à cêrca de 10 famílias distintas, feitos em nossos laboratórios, parecem indicar que tais filamentos estão ausentes no citoplasma de células sadias. Apenas no presente caso, esporàdicamente, feixes dêstes filamentos foram encontrados espalhados no citoplasma, em meio às partículas do VMNM.

Parece razoável aceitar que os filamentos e as inclusões densas estejam primàriamente implicados na síntese das partículas do VIMNM. Estas, à medida que fôssem sendo sintetizadas, acumular-se-iam nas áreas adjacentes, deslocando as organelas maiores, produzindo então as áreas diferenciadas no citoplasma, onde em geral êste vírus ocorre em grande quantidade.

Embora, do ponto de vista anatômico, algumas diferenças realmente existam entre tecidos foliares de plantas afetadas pelo VMNM e sadias, como presença de células necrosadas e certa desorganização nos tecidos, em concordância com estudos já realizados (4), estas ùnicamente não serviriam como elemento básico de 
diagnose desta moléstia, pois outras causas poderiam produzir efeitos similares. Também ao nível celular não se observou diferenças que permitissem o uso do microscópio óptico como meio adicional para caracterização das moléstias induzidas pelo VMNM.

\section{SPHEROIDAL PARTICLES ASSOCIATED WITH THE CASSAVA VEIN MOSAIC VIRUS}

\section{SUMMARY}

Spheroidal particles, $50-60 \mathrm{~m}_{\mu}$ in diameter, were found in quick preparations and in ultra-thin sections for electron microscopy, from leaves of cassava plants infected with the vein mosaic (CVMV). They were not found in preparations made from healthy plants, nor in symptomless leaves of infected plants, and are considered as representing the virus.

In ultra-thin sections of leaf tissues, CVMV particles were found dispersed in certain areas of the cytoplasm, rich in ribosomes, but poor in other cytoplasmic organelles, where sporadical small bundles of dense fibrils (7-10 $\left.\mathrm{m}_{\mu} \times 100-300 \mathrm{~m}_{\mu}\right)$ occur. Dense and fine granular masses $(0.3-3 \mu$ in diameter) were seen in a few instances, associated with the particles. It seems likely that both fibrils and the dense masses are primarily involved in the CVMV synthesis.

\section{LTTERATURA CITADA}

1. Andrewes, C. H. Classification of virus of vertebrates. Adv. Virus Res. $9: 271-279.1962$.

2. Bernhard, W. Comunicação pessoal.

3. BiLs, R. F. \& HaLL, C. E. Electron microscopy of wound-tumor virus. Virology $17: 123-130.1962$.

4. Costa, A. S. Observações sôbre o mosaico comum e o mosaico das nervuras da mandioca (Manihot utilissima Pohl.). J. Agronomia (Piracicaba) $3: 239-248.1940$.

5. Dales, S., Gomatos, P. J. \& Hsu, K. C. The uptake and development of Reovirus in strain L cells followed with labeled viral ribonucleic acid and ferritin-antibody conjugates. Virology 25:192-211. 1965.

6. Fukushi, T., Shikata, E. \& Kimura, I. Some morphological characters of rice dwarf virus. Virology 18:192-205. 1962.

7. Gomatos, P. J. \& Tamm, I. Animal and plant viruses with double-helical RNA. Proc. Natl. Acad. Sci. U.S.A. 50:878-885. 1963.

8. Kita.jima, E. W. A rapid method to detect particles of some spherical plant viruses in fresh preparations. J. Electronmicroscopy (Tokyo) $14: 219-221.1965$.

9 . — \& Costa, A. S. Microscopia electrônica de tecidos foliares de mandioca infetados pelo vírus do mosaico comum. Bragantia : no prelo.

10. —_ Oliveira, A. R. \& Costa, A. S. Ocorrência de um vírus esférico causando faixa amarela das nervuras da couve em São Paulo. Bragantia 24:219-230. 1965. 
11. LUFT, J. H. Improvements in epoxy resin embedding methods. J. Biophys. Biochem. Cytol. 9:409-414. 1961.

12. Lwoff, A., Horne, R. W. \& Tournier, P. A system of viruses. Cold Spring Harbor Symp. Quant. Biol. $27: 51-55.1962$.

13. Millonig, G. Studio sui fattori che determinano la preservazione della ultrastruttura. In From molecule to cell — Symposium on electron microscopy, (P. Buffa, Ed.), p.347-362. Roma. 1964.

14. Reynolds, E. S. The use of lead citrate at high $\mathrm{pH}$ as an electron opaque stain in electron microscopy. J. Cell Biol. 17:208-211. 1963.

15. RHIM, J. S., JordaN, L. E. \& MaYor, H. D. Cytochemical, fluorescent antibody and electron microscopic studies on the growth of Reovirus (ECHO 10) in tissue culture. Virology 17:342-355. 1962.

16. Richardson, N. K., JaRRET, L. \& PinKe, N. H. Embedding in epoxy resins for ultra-thin sectioning in electron microscopy. Stain Technology $35: 313-323.1960$.

17. Shikata, E., Orenski, S. W., Hirumi, H., Mitsuhashi, J. \& MaramoRoscr, $K$. Electron micrographs of wound-tumor virus in animal host and in a plant tumor. Virology 23:441-444. 1964.

18. Vasquez, G. \& Tournier, P. The morphology of Reovirus. Virology $17: 503-510.1962$.

19. Wildy, P., Stoker, M. G. P., McPherson, I. A. \& Horne, R. W. The fine structure of polyoma virus. Virology $11: 444-457,1960$. 